\title{
Primary cutis verticis gyrata
}

INSERM

\section{Source}

INSERM. (1999). Orphanet: an online rare disease and orphan drug data base. Primary

cutis verticis gyrata. ORPHA:671

Cutis verticis gyrata (CVG) is a progressive cutaneous disorder predominantly affecting males and characterized by hypertrophy and thickening of the skin of the scalp forming convoluted furrows with deep, tender, and cerebriform cutaneous folds. Hair is usually normal in the furrows and sparse on the folds. CG can be isolated (essential CVG) or associated with other abnormalities such as intellectual deficit, epilepsy, cataract, blindness, and deafness (non essential CVG). 